\title{
English Language Teachers' Practices of Textbook Adaptation Techniques
}

\author{
Novita Umi Pratiwi ${ }^{1}$, Jufrizal ${ }^{2}$, and Hamzah $^{3}$ \\ ${ }^{1}$ Universitas Negeri Padang, Padang, Indonesia, $ه($ (email), novitaumipratiwi@gmail.com \\ ${ }^{2}$-Universitas Negeri Padang, Padang, Indonesia, $ه$ (email), juf_ely@yahoo.com \\ ${ }^{3}$ Universitas Negeri Padang, Padang, Indonesia, $ه$ (email), zzahham@gmail.com
}

\begin{abstract}
The principal purpose of this article was to present the kinds of adaptive techniques used by the English language teachers in the English textbook for students of Senior and Vocational high schools which was developed by the center for curriculum and textbook development under the ministry of education and culture of Indonesia. To conduct the research, qualitative research design was employed and the data were analyzed qualitatively. The data were collected from five English language teachers through document, observation and interview. The findings of this study showed that the English teachers at SMKN 6 Padang commonly applied the textbook adaptation with various techniques. However, the techniques used by the English teachers were still limited when compared to the techniques of textbook adaptation given in the literature. The result of data analysis revealed that the most common techniques used by the English language teachers were the expansion, re-writing, and abridging techniques. On the other hand, the extension, subtraction, and reordering were rarely implemented by the English Teacher at SMKN 6 Padang. Based on the result of this research, there are several suggestions can be drawn by the researcher; while adapting the textbooks, teachers should be familiar with the textbook adaptation techniques and apply them properly in line with the various theories proposed by experts.
\end{abstract}

Keywords: Textbook adaptation, English teachers' practice, textbook adaptation techniques Written in English

\section{INTRODUCTION}

Textbooks are undoubtedly the primary materials used by teachers in language teaching. It cannot be denied that the language teachers use the textbook as one of the main guidance or resources in teaching. Hutchinson and Torres (1994: 315) state that the textbook is an almost universal element of (English language) teaching. It means that every English language teacher in the world uses textbooks. Therefore, textbooks chosen for English language teaching should correspond to the goals of the language course.

Every textbook used in language teaching should address the goals and appropriateness. Nevertheless, various problems with textbooks have been addressed by researchers. In a study conducted by Ebrahimpourtaher and Hamidi (2015) on the authenticity and adaptation in EFL materials, the underlying critic was that not all textbooks work in every learning time, situation, and for all of the individual learner who has different learning styles, interests, needs and beliefs as well as different social components. The other result of the research reported by Sudartini, Karmadi, and Diyanti (2016). There were some important points found in their study of teachers' perspectives related to the English teaching and learning materials for students of SMK majoring in art concentration. Firstly, the available textbooks for SMK do not fit the learners' needs, thus the teacher needs to find other materials. Secondly, regarding the skills and forms of texts, and types of activities used in the teaching and learning process, these particular learners are considered as having the same needs as those of SMA students.

Moreover, Fuller (1994) argues that "textbooks are produced by experts in the Ministry of Education to achieve the aims of the curriculum, but in reality, they may not fulfill the objectives they set themselves". The textbooks produced by the Ministry of Education are designed by experts. But, it cannot be denied that everything they include in the textbooks will not be appropriate for the entire language learning classroom. The classroom teacher is considered as the main individual who most understands the language learning condition. Thus, their skill in adaptation is highly required in language teaching.

The previous researches have proven that not all textbooks appropriate for all learners and adaptation from the teachers is needed and recommended by experts on English language teaching. There are many studies on textbook evaluation, but the adaptation on the inappropriate textbook conducted by the teachers seems to be limited. There is no local study which was conducted in 
relation to teachers' practices of textbooks adaptation found in Padang by the year 2019. Thus, this research attempts to analyze the English teachers' practices of textbook adaptation techniques.

According to McDonough, Shaw, and Mashuhara (2003:73), adaptation means matching materials to the need of students, teachers and administration's purpose. This opinion emphasizes that the material should appropriate not only for teachers but also for students and the purposes of the institution conducting the English language teaching and learning itself. These three aspects are the main factors in language learning. Thus, the textbook should be suitable for them. This opinion is very acceptable. It implies that there are many reasons for doing the textbook adaptation and it is much possible for materials to be adapted because the materials will not proper for different subject and purposes. the teachers can adapt every single parts of textbooks. Gabrielatos (2000) states that the following contents can be adapted: aims, topics, texts, visuals, guidelines and explanations, exercises /activities/tasks, games, quizzes, and questionnaires. This opinion emphasizes that the adaptation can be done in every part of textbooks. This is exactly an acceptable theory. Adaptation does not limit on the text in the textbook only. But every single part of textbooks can be adapted by the teachers, whenever they realize that those parts are inappropriate to the learners and learning process.

Materials adaptation techniques and activities might be various because of the different conditions in where the textbooks used. Cunningsworth (1995:137) states that there are three main areas involved in the process of adapting materials. First, the objective of activity should be consistent with the objective of the lesson or the activity will be replaced by another one. It means, when the activity is suitable, the teacher next considers the method implied to see whether the preassumption on how to do the activity fits the learners' learning. The materials will be adapted if the objectives and method are unsuitable and inconsistent. She adds that the teacher can also change the order of activities in the textbook in order to create variety, such as interaction pattern, a sequence of skill practice, level of difficulty, mood, etc. These only recommended in case the course book is unsuitable and insufficient style. Finally, the content of the activity should meet the learners' interest and motivation and culturally relevant, if not, they should be changed. This opinion includes what to be fulfilled before determining the adaptation of the material. It implies that evaluation should be implemented before adapting materials. The factors to be considered before conducting textbook adaptation are given clearly by this theory, but the practical technique of adaptation cannot be found yet. This theory is beneficial for the preparation stage only, and the other theory on the practical technique of textbook adaptation is needed.

Richards (1998:135) argues that the teachers use textbooks with the expectation that deletion, adaptation, and extension will be normally needed for the material to work effectively with their class. This opinion emphasizes that teachers should keep in mind that adaptation is a need for an English language classroom. We can agree with this opinion. It is correct that the first thing should keep in mind is that the textbook adaptation is normal process needed in language teaching and learning. We cannot deny that a textbook cannot be appropriate for learners with different needs and purposes. Making changes in the textbook material is allowed if the book cannot meet the need of teachers and students as well as the institution purposes.

McDonough, Shaw, and Mashuhara (2003: 7077) and Maley (1998:281) defined some alternatives in adaptation for teachers, they are; addition; extension and expansion, omission or deletion; subtraction and abridging, modification; re-writing, re-structuring, simplifying, and re-ordering. They define addition as supplementing the materials by adding the materials either by extension which means supplying more of the same within the methodological framework of the original materials, or by expansion which is defined as bringing about a qualitative as well as a quantitative changes. Omission can be used either by subtraction which refers to reducing the length of material that means making a quantitative change or by abridging which refers to deleting the material both qualitatively and quantitatively. Modification is defined as an internal change in the approach or focus of an exercise or another piece of material, and it is divided into two classifications: rewriting, in the form of revising the existing material, and restructuring which refers to changes in terms of grouping the students during the implementation of the tasks. Simplification refers to making the instructional tasks and activities easier for the students. Re-ordering is defined as adjusting the sequence of the contents within a unit, or taking units in a different sequence from that originally provided in the textbook. These techniques can be use either individually or combine with other.

\section{METHOD}

Based on the research problem as well as the type of data collected, the writer applied the descriptive qualitative method. This research was conducted at the SMKN 6 Padang. The sources of data were the respondents; in this case the five English language teachers at SMKN 6 Padang and the document; the students' notes. The researcher collected the data through the document checklist, interview, and observation.

The data analysis in this research was begun by analyzing the data from the documents; teachers' textbooks and students' notes. In analyzing the data from document the researcher begun by observing the students' notes. After that, the researcher compared those notes to the textbook used by the teachers. The researchers observed the students' notes that different from the textbook. After observing the differentiation, the researcher marked the adapted text, tasks, and explanation in the students' notes. In the next process, the researcher typed all the adapted materials in the students' notes and classified them into three techniques of textbook 
adaptation; addition, deletion, and modification. At last, the researcher displayed the data and drawn the conclusion on the most dominant and secondary techniques of textbook adaptation implemented by the teachers found based on the data from the documents.

In analyzing the data from the interview there were several steps followed by the researcher; firstly, all the interviews were listened to and the researcher took notes on three headings: teachers' reasons behind the textbook adaptation, how they adapt the textbooks and the level of teacher's adaptation. Secondly, notes of the parts of teachers' expressions directly answering the research questions were taken, categorized and analyzed. Thirdly, the researcher excluded the parts of the interviews which were off the topics of the investigation selectively. The most reflective and expressive comments made by the teachers in adapting the English teaching textbooks were transcribed and quoted in the data analysis section. Fourthly, in order to categorize the techniques of teachers in implementing textbooks adaptation, the data were categorized and analyzed by using indicators that were derived from theories or supporting literature.

\section{RESULT AND DISCUSSION}

The result of the research shows that the teachers commonly adapt the textbook material. Madsen and Bowen (1978) (as cited in McDonough, Shaw, and Mashuhara 2003: 75) mention that the good teacher is constantly adapting. In this research the teachers found to adapt the materials in the textbook, they will be categorized as good teachers if they adapt constantly. The constantly adapting means taking adaptation as the parts of teachers' daily by considering reasons for adaptation, and using the various techniques as proposed by the experts. This is supported by Richards (1998:135), who argues that the teachers use textbooks with the expectation that deletion, adaptation, and extension will be normally needed for the material to work effectively with their class.

In general, the most commonly used techniques for textbook adaptation were the addition; expansion, deletion/ omission; abridging, and modification; rewriting. There was also another technique implemented by the teacher in a limited amount; simplifying and restructuring. On the other hand, the extension, subtraction, and re-ordering were rarely implemented by the English Teacher at SMKN 6 Padang. Regarding the omission in adaptation, that implemented dominantly by the teachers at SMKN 6 Padang, Harmer (1998:111), states that omitting the lesson from a textbook is normal, there is nothing wrong with omitting lessons from textbooks, teachers do it all the time. The teachers also develop, pick and choose the material in the textbook. However, he continues that the teachers should be careful and try not to omit too many pages, because the students may begin to confuse why they are using the book if they are not following it.

The findings of the study also revealed that the subjects of this study are aware of textbook adaptation. They adapt some textbook materials with various techniques. But, the teachers do not aware of the names of specific techniques of textbook adaptation although they used those techniques. There are techniques that teachers should use while adapting textbook materials as mentioned in the literature review. These include addition; extension and expansion, deletion/ omission; subtraction and abridging, and modification; re-writing, re-structuring, simplifying and re-ordering. However, the subjects of this study did not know them properly. This finding is also consistent with what Littlejohn (1998:15) found out that "lack of professional development training" could restrain teachers from adapting and supplementing textbook materials. The lack of professional development can be the cause of teacher unawareness on the terms used in the techniques of adaptation.

These findings oppose the findings of Addisu Yilhal (2012) because, in his study, he concluded that teachers completely avoided textbook adaptation because of fear of being called lazy and incompetent and they had a negative attitude towards it. Therefore, from his conclusion, one can easily understand that teachers were conscious about textbook adaptation but they avoided it. Thus, this shows that the findings of the previous study contradict with the findings of the current study. However, these findings are in accordance to the research of Melisew Tibebu in 2017 on the EFL teachers' practice of adapting textbook materials: the case of five selected high schools in Ilu Aba Bor zone, Ethiopia. The findings of this study revealed that the subjects of this study are not aware of textbook adaptation though they adapt some textbook materials unconsciously, without considering the principles and theories of textbook adaptation.

According to the result of the documents, interview, and observation, the teachers at SMKN 6 Padang implement the various technique of adaptation. But, they need to explore and implement the other technique to enrich their adaptation. This research also supports other previous research conducted by Zelis Coban (2001) regarding the experienced and novice English language teachers' use of textbook adaptation strategies at Gazi University. The results of the study revealed that the experienced and novice teachers used limited types of adaptive techniques when compared to the alternatives given in the literature.

This study was conducted within one school, and the numbers of the participants were limited to five English teachers. Thus, the generalization of the results for this study is limited. There are also some limitations originated from the data collection instrument. The observation was conducted in a limited meeting; the researcher observed the implementation in five meetings. Thus, it would be more effective if the researcher conduct more observation to increase the quality of the data.

The results of this research imply that teachers adapted the textbook due to their beliefs and understandings by taking the students as the main consideration for their adaptation. Although they use various techniques for adaptation, their techniques are actually limited when compared to the alternatives given in the literature. Based on the result of this research, there are several suggestions can be drawn by the researcher. 
While adapting textbook materials, teachers should use varieties of techniques flexibly. In other words, teachers should be familiar with textbook adaptation techniques and apply them in line with the principles and theories that various scholars proposed. the researcher suggests that the teachers should get training on the principles and practices of textbook adaptation either through certified teacher program or other programs, whereas students who study teaching as a field in different universities should get the training by including textbook adaptation as a course of study in the universities curriculum all over the country. Further inclusive research should be conducted in the field so as to know how teachers as a whole in Padang or other cities implement the textbook adaptation.

\section{CONCLUSION}

In this research, attempts have been made to analyze English language teachers' practices of textbook adaptation at SMKN6 Padang. Therefore, based on the data obtained through the instruments the following major conclusions could be drawn. The most commonly used techniques for textbook adaptation were the deletion/ omission; abridging, addition; expansion, and modification; re-writing technique. On the other hand, the extension, subtraction, and re-ordering were rarely implemented by the English Teacher at SMKN 6 Padang. The findings of the study revealed that the subjects of this study are aware of textbook adaptation. They adapt some textbook materials with various techniques. But, the teachers do not aware of the names of specific techniques of textbook adaptation although they used those techniques.

Based on the result of this research, there are several suggestions can be drawn by the researcher. While adapting textbook materials, teachers should use varieties of techniques flexibly. In other words, teachers should be familiar with textbook adaptation techniques and apply them in line with the principles and theories that various scholars proposed. the researcher suggests that the teachers should get training on the principles and practices of textbook adaptation either through certified teacher program or other programs, whereas students who study teaching as a field in different universities should get the training by including textbook adaptation as a course of study in the universities curriculum all over the country. Further inclusive research should be conducted in the field so as to know how teachers as a whole in Padang or other cities implement the textbook adaptation.

\section{ACKNOWLEDGMENTS}

I would like to offer heartiest gratitude to all those who support me in conducting this study. Firstly, I would like to say Alhamdulillah all praise to Allah SWT, for giving me strength and encouragement during all the moments in completing this research. Secondly, I would like to convey millions appreciations to who give me an opportunity to study at State University of Padang. Thirdly, I would like to express my sincere gratitude to my advisors Prof. Dr. Jufrizal, M.Hum and Prof. Dr. Hamzah,
M., M.M, whose valuable guidance and expertise have guided me until the end of this study. Finally, I would like to thank my dear parents for being there behind my dream, my sister, my brother, and my friends that gave me lots of support during this study.

\section{REFERENCES}

[1] Cunningsworth, A. (1995). Choosing Your Coursebook. Oxford: Heineman.

[2] Ebrahimpourtaher, Adel and Esmaeel Hamidi. (2015). Authenticity and adaptation in EFL materials. International Archive of Applied Sciences and Technology IAAST, Vol 6 [2], June 2015

[3] Fuller, B. (1994). Raising School Effect While Ignoring Culture? Local condition and the Influence of Classroom Tools, Rules, and Pedagogy. Review Of Educational Research 64 (1) $119-157$.

[4] Graves, K. (2000). Designing Language Courses: A Guide for Teachers. Boston: Heinle\&Heinle.

[5] Harmer, J. (1991). The Practice of English Language Teaching. Longman

[6] Hutchinson, T, and Torres. (1994). The Textbook as Agent of Change. ELT Journal vol 48

[7] Littlejohn, A. (1998). The Analysis of Teaching Materials: Inside the Trojan Horse. Cambridge: Cambridge University Press.

[8] McDonough, J., \& Shaw, C, and Mashuhara. (2003). Materials and Methods in ELT: A Teachers' Guide. London: Blackwell.

[9] Richards, J. C. (1998). Beyond Trainin. Cambridge: Cambridge University Press.

[10] Sudartini, Siti, Siwi Karmadi K, and B Yuniar Diyanti. (2016). English Teaching Materials for SMK Students Majoring in Arts: Teachers' Perspectives. Proceeding The 2nd International Conference On Teacher Training and Education at Sebelas Maret University. Volume 2 No. 1

[11] Tibebu, Melisew. (2017). EFL Teachers' Practice of Adapting Textbook Materials: The Case of Five Selected High Schools in ILU ABA BOR Zone. International Journal of Social Science and Humanities Research. Vol. 5, Issue 2, pp. 253276.

[12] Yilhal, Addisu. (2012). Teachers' Attitude to, and Practices of adapting and Supplementing a Textbook.Addis Ababa University. 